Удк 676.15.017.6

\title{
ФИЗИКО-ХИМИЧЕСКИЕ ОСНОВЫ ПОВЕРХНОСТНОЙ ПРОКЛЕЙКИ БУМАГИ ПОЛИКАТИОННЫМ ПОЛИМЕРОМ
}

\author{
(ㄱ) О.С. Вдовина, С.Ю. Кожевников, И.Н. Ковернинский" \\ ООО «СКИФ Спешиал Кемикалз», Восточная промзона, 7, Дзержинск \\ Нижегородской обл., 606000 (Россия), e-mail: kovern@list.ru
}

\begin{abstract}
Статья посвящена теоретическим представлениям о гидрофильно-гидрофобном состоянии бумаги и управляемом влиянии на него поверхностной проклейкой новым полимерным клеем. Рассмотрены основные факторы процесса нанесения клея, влияющие на гидрофильную поверхность бумаги - температура, концентрация клея, микрорельеф и капиллярность бумаги. Проанализированы функциональные гидрофильные и гидрофобные радикалы действующего вещества полимерного клея и их влияние на образование гидрофобного слоя на поверхности бумаги.

Ключевые слова: бумага, поверхностная проклейка, гидрофобность, гидрофильность, поверхностное натяжение, полимер, сополимер, поликатионный полимер, гидрофильные радикалы, гидрофобные радикалы, когезия, адгезия, водно-полимерная оболочка, гидрофобный слой.
\end{abstract}

\section{Введение}

Бумага (картон) благодаря гидрофильности растительного волокна и капиллярно-пористой структуре при выработке без проклейки отличается высокой гидрофильностью и гигроскопичностью. В то же время к большинству видов бумаги предъявляются требования ограниченного впитывания воды и поглощения влаги из воздуха. Задача ограничения впитывания воды или гидрофобизация бумаги решается в процессе проклейки, осуществляемой в виде проклейки в массе или поверхностной проклейки, или их сочетанием [1]. Проклейка в массе основана на взаимодействии волокна с клеем до формования бумаги, а поверхностная проклейка основана на взаимодействии с клеем поверхности сформованной бумаги. В данной работе остановимся на основных физико-химических основах поверхностной проклейки бумаги новым синтезированным поликатионным полимером.

\section{Гидрофильно-гидрофобное состояние поверхности бумаги}

Ниже будут использоваться следующие обозначения: $\theta$ - краевой угол смачивания; поверхностное

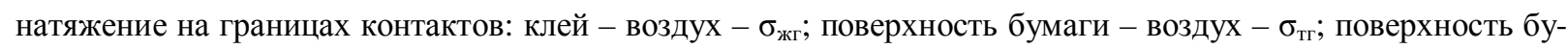
маги - клей $-\sigma_{\text {тж}}$.

Сформованная бумага без применения какого-либо метода проклейки, как уже указывалось, является гидрофильным материалом. Ее поверхность и внутренняя структура неограниченно (полностью) смачивается водой - краевой угол смачивания $(\theta)$ не определяется, а наносимый на поверхность клей растекается по ней в тонкую пленку, которая полностью обволакивает поверхность бумаги. Протекание процесса полного смачивания выполняется при условии $-\sigma_{\text {тг }}>\sigma_{\text {тж}}+\sigma_{ж г} \cos \theta$. И в этом случае на поверхности бумаги образуется клеевой слой - водно-полимерная оболочка.

Вдовина Ольга Сергеевна - заведующая химической лабораторией, e-mail: olga_vdovina@skif.ru Кожевников Сергей Юрьевич - кандидат технических наук, доцент, e-mail: skif.special.chemicals@gmail.com Ковернинский Иван Николаевич - доктор технических наук, профессор, академик РAEH, e-mail: kovern@ list.ru
Гидрофобизация бумаги в процессе поверхностной проклейки переводит ее в ограниченно смачиваемый водой материал. Физикохимическими количественными величинами для характеристики гидрофобности поверхности явля-

\footnotetext{
* Автор, с которым следует вести переписку.
} 
ются $\theta$ (условие гидрофобности $90^{\circ}>\theta>0^{\circ}$ ) или $\mathrm{W}_{\mathrm{A}}$. Для ограниченного смачивания должны выполняются условия: $90^{\circ}>\theta>0^{\circ} u 2 \sigma_{ж г}>\mathrm{W}_{\mathrm{A}}>\sigma_{ж г}$, где: $\mathrm{W}_{\mathrm{A}}-$ удельная работа адгезии воды к поверхности бумаги [2]. Как видно из условий, придаваемая степень гидрофобности имеет широкий предел, практически от полного смачивания (гидрофильный материал - $\theta$ несколько градусов) - до полного несмачивания (гидрофобный материал $-\theta$ вблизи $\left.90^{\circ}\right)$. Движущей силой смачивания бумаги водой $(\mathrm{U})$ является разность $\sigma_{ж г}$ - $\sigma_{\text {тг }}$. При отрицательном значении $U\left(\sigma_{\text {тг }}>\sigma_{\text {жг }}\right.$ ), поверхность гидрофильная, самопроизвольно неограниченно смачивается водой с высвобождением энергии, а при положительном значении $U\left(\sigma_{\text {жг }}>\sigma_{\text {тг }}\right.$ ), поверхность гидрофобная, а смачивание возможно только при подводе энергии извне.

Учитывая рассмотренные условия и закономерности гидрофильно-гидрофобного состояния поверхности бумаги, можно сформулировать задачу поверхностной проклейки бумаги следующим образом: придание поверхности бумаги заданной гидрофобности.

Кратко рассмотрим процессы, обеспечивающие решение задачи.

\section{Основы теории гидрофобизации бумаги}

Результатом поверхностной проклейки бумаги является заданная гидрофобность поверхности, количественно характеризуемая каким-либо из методов определения - степень проклейки (чернильноштриховой или индикаторный методы), впитываемость воды при одностороннем смачивании (метод Кобба) [3], по краевому углу смачивания, геометрическим размерам капли воды на поверхности и др.

Любая из характеристик гидрофобности (гидрофильности) определяется равновесным состоянием удельных свободных поверхностных энергий на границе линии трехфазного контакта (ЛТК), одним из выражений которых являются поверхностные натяжения $-\sigma_{\text {жг }}, \sigma_{\text {тг }}$ и $\sigma_{\text {тж. }}$.

Таким образом, управление гидрофобностью поверхности бумаги сводится к целевому воздействию на поверхностное натяжение контактирующих сред. В результате поверхностной обработки бумаги клеем следует достичь положительного значения движущей силы смачивания поверхности бумаги водой $\left(\mathrm{U}=\sigma_{\text {жг }}\right.$ $-\sigma_{\text {тг }}$. Это возможно при условии $\sigma_{\text {жг }}>\sigma_{\text {тг }}$. Выполнение данного условия обеспечивается повышением $\sigma_{ж г}$ или понижением $\sigma_{\text {тг }}$, или одновременным повышением и понижением этих величин.

Как указывалось, гидрофобизация гидрофильной поверхности бумаги с помощью поверхностной проклейки осуществляется нанесением на поверхность клея. В данной работе рассматривается гидрофобизация бумаги водным раствором нового поликатионного полимера. Полимер получают методом полимеризационного синтеза ряда мономеров алкеновых метакриловых производных, включающих мономер с явно выраженной катионактивной функциональной группой. Таким образом, действующим веществом полученного продукта является водорастворимый катионный полимакромолекулярный сополимер алкеновых метакриловых производных с полигетерогидрофобными радикалами в линейной цепи. Товарный продукт на основе данного сополимера - это клей для поверхностной проклейки бумаги, представляющий собой водный раствор концентрацией действующего вещества 18-23\% и получивший фирменное название «Ультрасайз SP 312». Расход клея учитывается по товарному продукту и находится в пределах $0,5-1,5$ кг/т бумаги. Следовательно, расход по действующему веществу при концентрации, например, $20 \%$ и расходе 1 кг/т составляет 0,2 кг/т или 200 г/т. Учитывая двустороннее нанесение и количество квадратных метров в 1 т бумаги (например, для массы бумаги 140 г/м² это $714 \mathrm{~m}^{2}$ ), расход клея на $1 \mathrm{~m}^{2}$ составит 0,14 г на одну сторону.

Укажем, что водные растворы полимеров, подобные клею «Ультрасайз SP 312», относятся к термодинамически стабильным молекулярным коллоидным системам [4] и рассматриваются как коллоидные системы.

\section{Основные стадии и механизм поверхностной проклейки бумаги}

При поверхностной проклейке бумаги следует рассматривать следующие основные стадии: нанесение клея на поверхность бумаги и его закрепление; образование поверхностного гидрофобного слоя. Задача нанесения клея предусматривает равномерное распределение заданного количества раствора полимера (макромолекул сополимера) по гидрофильной поверхности бумаги, а задача второй стадии - это взаимодействие полимера и поверхности бумаги с превращением водно-полимерной оболочки в поверхностный гидрофобный слой.

Нанесение клея на поверхность бумаги и его закрепление. Этот процесс зависит от межмолекулярного взаимодействия контактирующих сред - бумаги, клея и воздуха [2]. В момент нанесения клея поверхность бумаги отличается полной смачиваемостью, т.е. $\sigma_{ж т}-\sigma_{\text {тг }}$ имеет отрицательное значение, а, следовательно, клей 
самопроизвольно и равномерно растекается по поверхности. Такое развитие процесса на поверхности бумаги на стадии нанесения клея является предпочтительным и определяется свойствами клея и свойствами бумаги.

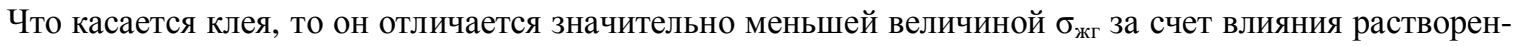
ного полимера и высокой температуры поверхности бумаги в зоне нанесения клея. Величина $\sigma_{ж г}$ в клее уменьшается за счет превалирования сил межмолекулярного взаимодействия воды над межмолекулярным взаимодействием воды и гидрофобных частей макромолекул. Разность взаимодействия обусловливает вытеснение гидрофобных радикалов и в целом макромолекул сополимера из объема клея в пограничный слой. В результате поверхностное натяжение смешанной фазы (воды и макромолекул сополимера) в пограничном слое клея уменьшается. Уменьшенное $\sigma_{\text {жг }}$, согласно движущей силе смачивания, усиливает растекание клея по поверхности и тем самим способствует более равномерному и полному распределению клея, следовательно, сополимера по поверхности бумаги. Роль высокой температуры поверхности бумаги, в условиях реального процесса в пределах $100-120{ }^{\circ} \mathrm{C}$, заключается в значительном понижении $\sigma_{ж г}$ клея

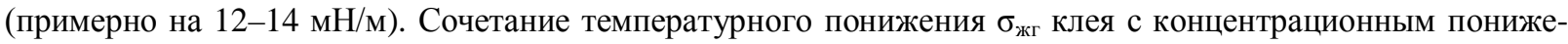
нием $\sigma_{\text {жг }}$ сополимером является определяющим фактором быстрого, равномерного и полного распределения клея по поверхности бумаги.

Наряду со свойствами клея на его нанесение влияют свойства поверхности бумаги.

К основным свойствам поверхности бумаги, влияющими на нанесение клея, отнесем: микрорельеф, пористость, влажность, химическую и физико-химическую активность, электроповерхностную активность.

Поверхность бумаги имеет определенный микрорельеф (микрогеометрию), характеризуемый шероховатостью или гладкостью. Как правило, фактическая (эффективная) площадь бумаги $\left(\mathrm{S}_{э \phi}\right)$ за счет шероховатости значительно больше площади ее проекции на идеализированную (гладкую) поверхность $\left(\mathrm{S}_{\mathrm{r}}\right)$. Величина шероховатости измеряется коэффициентом шероховатости $\mathrm{K}_{э \phi}=\mathrm{S}_{э \phi} / \mathrm{S}_{\text {г }}($ Кэф $>1)$. Шероховатость поверхности влияет на смачиваемость поверхности посредством краевого угла смачивания $\theta$. Связь между краевыми углами смачивания на шероховатой (эффективной) поверхности $\theta_{э ф}$ и на гладкой поверхности дает уравнение Вензеля-Дерягина: $\cos \theta_{\ni \phi}=K_{э \phi} \cos \theta_{\text {г }}[5]$. Поскольку $K_{\text {эф }}>1$, то по модулю $\left|\cos \theta_{\ni ф}>\cos \theta_{г}\right|$. Таким образом, из рассмотренных данных видно, что шероховатость повышает смачивание $\left(\theta_{\text {эф }}<\theta_{\text {г }}\right)$ при $\theta<90^{\circ}$ и понижает смачивание (повышает гидрофобность) поверхности $\left(\theta_{э ф}>\theta_{г}\right)$, при $\theta>90^{\circ}$. При нанесении клея на поверхность бумаги реализуется процесс повышения смачиваемости.

Пористость бумаги - также фактор, повышающий эффект смачивания поверхности бумаги клеем. Морфологию пористости бумаги относят к губчатым набухающим разнороднопористым структурам, в которой системы пустот и каналов образуются сплошной сеткой твердой фазы - волокном (в отсутствие наполнителя) [6]. Пористые тела классифицируют по преимущественному размеру пор на микропористые (поры до 2 нм), мезопористые (от 2 до 50 нм) и макропористые (свыше 50 нм) [7, 8]. Общий объем пор для различных видов бумаги различается в широких пределах - от 30 до 70\%. В бумагах, которые подвергаются гидрофобизации методом поверхностной проклейки, объем пор находится в пределах 50-60\% со средним радиусом пор 0,16-0,18 мкм (160-180 нм). В бумаге без поверхностной проклейки превалируют макропоры или просто поры - это пространства между волокнами, заполненные воздухом и влагой. Мезопоры и микропоры, или капилляры - мельчайшие пространства неопределенной формы, также имеются в бумаге, пронизывая ее структуру и внутреннюю структуру целлюлозного и иного растительного волокна. Они также заполнены водой и воздухом.

Рассмотренная морфология пористости имеет вполне определенное значение при поверхностной проклейке. Пористости отдается предпочтение в механизме проникновения клея в структуру бумаги, в основу которого положен перенос жидкости по межволоконной капиллярно-пористой системе [9]. Принимая эту точку зрения, укажем, что проникновение клея в структуру бумаги - это обобщающий процесс, который отличается сложностью его составляющих: капиллярные явления (собственно перенос жидкости), адсорбция воды и полимера, диффузия компонентов, влияние воздуха, заключенного в порах. Однако рассмотрение составляющих - это тема другой работы.

Традиционно клей наносят на сформованный слой бумаги с сухостью в пределах 88-92\% [1, 10]. Сухость (влажность) бумаги влияет на скорость и глубину проникновения клея в структуру бумаги [1, 11]. Пределы сухости 88-92\% (влажность 8-12\%), при которой бумага и клей приводятся в контакт, показывают то, что к моменту контакта в бумаге содержится только прочносвязанная влага, находящаяся преимущественно в микрокапиллярах. Следовательно, в механизме проникновения клея остается большая доля капиллярных эффектов - всасывания клея капиллярными силами за счет полного смачивания внутренней 
поверхности капилляров. Эти эффекты также повышают проникновение клея в толщу бумаги. Одновременно происходит некоторое увлажнение бумаги, которое оценивается пределами сухости 75-85\% [1].

Как показано в работе [12], глубина проникновение клея в бумагу главным образом зависит от концентрации и свойств полимера в клее, удельной плотности бумаги и времени контакта клея с поверхностью бумаги. Исследованиями установлено, что клей успевает проникать на глубину 90-130 мкм (90-130·10 нм). Таким образом, в этом пределе проникновения клея в структуру бумаги находится слой активного взаимодействия клеевой водно-полимерной оболочки с волокном.

Химическая, физико-химическая и электроповерхностная активность поверхности бумаги определяется микрорельефом (активными энергетическими центрами адсорбции воды и сополимера), поверхностной плотностью и активностью функциональных групп волокна. Эта тема будет подробно рассмотрена в следующем труде.

Образование поверхностного гидрофобного слоя. Поверхностный слой водно-полимерной оболочки с волокном в условиях высокой температуры и интенсивного удаления влаги из бумаги в коротком интервале времени превращается в поверхностный гидрофобный слой. Гидрофобность придается макромолекулами сополимера, являющимся действующим веществом клея. Учитывая малые расходы полимера в пределах $0,1-$ $0,2 \Gamma / \mathrm{M}^{2}$, можно утверждать, что гидрофобизация поверхности осуществляется мономолекулярной пленкой полимера с дискретным (точечным, мозаичным) распределением гидрофобных радикалов и групп по поверхности бумаги. При этом в соответствии с закономерностями гидрофобного взаимодействия [13] макромолекулы сополимера, сконцентрированные в граничном слое водно-полимерной оболочки на поверхности бумаги, остаются ориентированными гидрофобными участками к воздушной фазе. Гидрофильные функциональные группы и части макромолекул взаимодействуют с гидрофильными гидроксильными группами и участками волокна. Поликатионный характер макромолекул сополимера обеспечивает почти мгновенную фиксацию и закрепление их с полианионной поверхностью бумаги силами электростатического притяжения. Удаленная влага до конечной влажности бумаги 6-8\% обеспечивает обнажение гидрофобных точечных участков на поверхности и тем самым создает определенное гидрофобно-гидрофильное состояние поверхности.

Характерные сополимеру функциональные радикалы приведены в таблице. Как видно в таблице 1, в макромолекуле действующего вещества клея содержатся полярные функциональные радикалы, обладающие гидрофильностью, и неполярные гидрофобные радикалы. При этом гидрофильные и гидрофобные радикалы имеют разное строение и различаются уровнем гидрофильности и гидрофобности. Поверхность бумаги также характеризуется мозаичностью распределения гидрофильных и гидрофобных участков. Следуя закономерностям, вода и гидрофильные радикалы сополимера будут ориентироваться и сцепляться с гидрофильными участками поверхности, а гидрофобные радикалы будут сцепляться с гидрофобными участками. Следовательно, имеет место избирательное смачивание поверхности бумаги. Поскольку гидрофильные и гидрофобные радикалы сополимера в цепи макромолекул чередуются, то сополимер будет равномерно распределяться по поверхности бумаги.

Таким образом, в условиях нанесении клея на поверхность бумаги температурным, концентрационным, микрорельефным и капиллярно-пористым факторами $\sigma_{\text {жг }}$ существенно снижается. Это обеспечило равномерное распределение сополимера и его гидрофобных радикалов на поверхности бумаги. Удаление влаги до влажности бумаги 6-8\% и высокая температура бумаги превращают водно-полимерную оболочку с поверхностным слоем волокна в гидрофобный слой. При контакте данного слоя с водой и воздухом межмолекулярные силы воды (силы когезии) превалируют над межмолекулярными силами взаимодействия воды с поверхностью (силы адгезии), т.е. выполняется условие гидрофобности поверхности $\sigma_{\text {жг }}>\sigma_{\text {тг }}$.

Иллюстрация состояния капли воды на гидрофобизированной клеем поверхности бумаги при контакте трех фаз «твердая поверхность - вода - воздух» в условиях равновесия представлена на рисунке.

Функциональные радикалы линейной цепы макромолекул сополимера

\begin{tabular}{|c|c|c|c|}
\hline \multicolumn{2}{|c|}{ Гидрофильные } & \multicolumn{2}{|c|}{ Гидрофобные } \\
\hline Структура & Название & Структура & Название \\
\hline $\begin{array}{c}-\mathrm{COOH} \\
-\mathrm{COO}\left(\mathrm{R}_{1}, \mathrm{R}_{2}, \mathrm{R}_{3}, \mathrm{R}_{4}\right), \\
\text { где: один из радикалов } \\
+ \\
\mathrm{R}_{2}\left(-\mathrm{CH}_{2} \mathrm{CH}_{2} \mathrm{~N}_{\left.\left(\mathrm{CH}_{3}\right)_{2}\right)}\right. \\
\mathrm{R}_{3}\left(-\mathrm{COOC} \mathrm{H}_{5}\right) \\
\mathrm{R}_{4}\left(-\mathrm{COO}\left(\mathrm{CH}_{2}\right)_{17} \mathrm{CH}_{3}\right)\end{array}$ & $\begin{array}{l}\text { карбоксильная } \\
\text { сложноэфирная }\end{array}$ & $\begin{array}{c}-\left[\mathrm{CH}_{2}-\mathrm{CR}_{1} \mathrm{R}_{2}\right]_{\mathrm{n}}- \\
-\left[\mathrm{CH}_{2}-\mathrm{CR}_{1} \mathrm{R}_{3}\right]_{\mathrm{m}}- \\
-\left[\mathrm{CH}_{2}-\mathrm{CR}_{1} \mathrm{R}_{4}\right]_{\mathrm{k}}- \\
\mathrm{R}_{1}-\mathrm{CH}_{3} \\
-\mathrm{C}_{6} \mathrm{H}_{11} \\
-\left(\mathrm{CH}_{2}\right)_{17} \mathrm{CH}_{3}\end{array}$ & $\begin{array}{l}\text { углеводородная } \\
\text { цепь } \\
\text { метил } \\
\text { циклогексил } \\
\text { стеарил }\end{array}$ \\
\hline
\end{tabular}


$$
\sigma_{\text {жг }}
$$

3

Капля воды при трехфазном контакте:

1 - вода; 2 - бумага; 3 - воздух; $\theta$ - краевой угол

смачивания поверхности; $\beta$ - краевой угол

смачивания внутренней структуры; $\mathrm{h}_{0}$ - высота

капли над поверхностью бумаги; $\mathrm{h}_{1}$ - глубина

впитывания воды

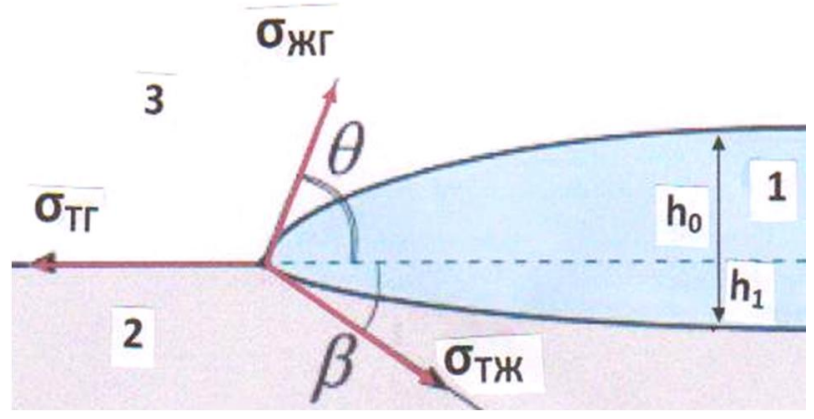

На рисунке видно, что капля воды ограниченно растекается по гидрофобной поверхности и ограниченно проникает в пограничный слой бумаги. Высота капли над поверхностью бумаги $\left(\mathrm{h}_{0}\right)$, глубина впитывания воды в пограничный слой $\left(\mathrm{h}_{1}\right)$ и краевой угол смачивания $\theta$ характеризуют величину гидрофобности бумаги. Гидрофобизацию поверхности бумаги при поверхностной проклейке осуществляют так, чтобы получить заданную величину гидрофобности.
\end{abstract}

\title{
Выводы
}

1. Сформованная бумага без применения проклейки является предельно гидрофильным материалом, для которого выполняется условие $\sigma_{\text {тг }}>\sigma_{\text {жг }}$.

2. Клей для гидрофобизации поверхности гидрофильной бумаги представляет собой водный раствор катионного полимакромолекулярного сополимера алкеновых метакриловых производных с полигетерогидрофобными радикалами в линейной цепи.

3. В условиях контакта клея и поверхности бумаги, температурным, концентрационным, микрорельефным и капиллярно-пористым факторами $\sigma_{\text {жг }}$ существенно снижается, создавая максимально благоприятное образование поверхностного слоя водно-полимерной оболочки с волокном.

4. Поверхностный слой водно-полимерной оболочки с волокном в условиях высокой температуры и интенсивного удаления влаги из бумаги, в коротком интервале времени превращается в поверхностный гидрофобный слой.

5. При контакте гидрофобного слоя с водой и воздухом межмолекулярные силы воды превалируют над межмолекулярными силами взаимодействия воды с поверхностью, т.е. выполняется условие гидрофобности поверхности $\sigma_{\text {жг }}>\sigma_{\text {тг }}$.

\section{Сиисок литературь}

1. Крылатов Ю.А., Ковернинский И.Н. Проклейка бумаги. М., 1987. 288 с.

2. Вдовина О.С., Кожевников С.Ю., Ковернинский И.Н. Теоретические основы управления гидрофильногидрофобным состоянием бумаги при поверхностной проклейке // Вестник Казанского технологического университета. 2014. №22. С. 92-96.

3. Крылатов Ю.А., Ковернинский И.Н. Материалы для проклейки бумаги и картона. М., 1982.84 с.

4. Ostwald Wo. Die Welt der vernachlassigten Dimensionen. Drezden-Leipzig: Vertrag Th. Steinkopf, 1944. S. 236-246.

5. Щукин Е.Д., Перцов А.В., Амелина Е.Л. Коллоидная химия. М., 2004. 445 с.

6. Дубинин М.М. // Известия АН СССР. Сер. хим. 1981. №1. С. 9-23.

7. Грег С. Адсорбция, удельная поверхность, пористость : пер. с англ. 2-е изд. М., 1970. 408 с.

8. Хейфец Л.И., Неймарк А.В. Многофазные процессы в пористых средах. М., 1982.320 с.

9. Williams G.J., Drummond J.G. Preparation of Large Sections for the Microscopical Study of Puper Structure // Proceeding of 1994 Papermakers Conference. Tappi Press. 1994. Book 2. Pp. 517-523.

10. Фляте Д.М. Технология бумаги. М., 1988. 440 с.

11. Петров А.П. Поверхностная проклейка бумаги и картона. М., 1968. 80 c.

12. Shirazi M., Esmail N., Garnier G., T.M.G. van de Ven. Starch Penetration into Paper in a Size Press // J. of Dispersion science and Technology. 2004. Vol. 25, N4. Pp. 457-468.

13. Пчелин В.А. Гидрофобное взаимодействие в дисперсных системах. М., 1976. 64 с.

Поступило в редакцию 18 декабря 2014 г. 
Vdovina O.S., Kozhevnikov S.Iu., Koverninskiy I.N. ${ }^{*}$ PHYSICOCHEMICAL BASIS OF SURFACE SIZING PAPER POLYCATIONIC POLYMER

Co.Ltd «SKIF Special Chemical», Vostochnaya promzona, 7, Dzerzhinsk, Nizhny Novgorod region, 606000 (Russia), e-mail: kovern@list.ru

The article is devoted to theoretical notions of hydrophilic-hydrophobic paper and state-controlled impact on a surface sizing new polycationic polymer glue. The main factors influencing the process of applying adhesive to the hydrophilic surface of the paper - the temperature, the concentration of glue, and capillary micro-relief of the paper. Analyzed functional hydrophilic and hydrophobic radicals of the active substance of adhesive polymer and their influence on the formation of a hydrophobic layer on the surface of the paper.

Keywords: paper, surface sizing, hydrophobicity, hydrophilicity, surface tension, a polymer, a copolymer, a polycationic polymer, hydrophilic radicals, the hydrophobic radicals, cohesion, adhesion, water-shell polymer, a hydrophobic layer.

\section{References}

1. Krylatov Iu.A., Koverninskii I.N. Prokleika bumagi. [Paper sizing]. Moscow, 1987, 288 p. (in Russ.).

2. Vdovina O.S., Kozhevnikov S.Iu., Koverninskii I.N. Vestnik Kazanskogo tekhnologicheskogo universiteta, 2014, no. 22, pp. 92-96. (in Russ.).

3. Krylatov Iu.A., Koverninskii I.N. Materialy dlia prokleiki bumagi i kartona. [Materials for the sizing of paper and paperboard]. Moscow, 1982, 84 p. (in Russ.).

4. Ostwald Wo. Die Welt der vernachlassigten Dimensionen. Drezden-Leipzig: Vertrag Th. Steinkopf, 1944. S. $236-246$.

5. Shchukin E.D., Pertsov A.V., Amelina E.L. Kolloidnaia khimiia. [Colloidal chemistry]. Moscow, 2004, 445 p. (in Russ.).

6. Dubinin M.M. Izvestiia AN SSSR. Ser. khim., 1981, no. 1, pp. 9-23. (in Russ.).

7. Greg S. Adsorbtsiia, udel'naia poverkhnost', poristost'. [Adsorption, the specific surface area, porosity]. Moscow, 1970, 408 p. (in Russ.).

8. Kheifets L.I., Neimark A.V. Mnogofaznye protsessy v poristykh sredakh. [Multiphase processes in porous media]. Moscow, 1982, 320 p. (in Russ.).

9. Williams G.J., Drummond J.G. Proceeding of 1994 Papermakers Conference. Tappi Press, 1994, Book 2, pp. 517-523.

10. Fliate D.M. Tekhnologiia bumagi. [Technology papers]. Moscow, 1988, 440 p. (in Russ.).

11. Petrov A.P. Poverkhnostnaia prokleika bumagi i kartona. [Surface sizing of paper and paperboard]. Moscow, 1968, 80 p. (in Russ.).

12. Shirazi M., Esmail N., Garnier G., T.M.G. van de Ven. J. of Dispersion science and Technology, 2004, vol. 25, no. 4, pp. 457-468.

13. Pchelin V.A. Gidrofobnoe vzaimodeistvie v dispersnykh sistemakh. [Hydrophobic interaction in dispersed systems]. Moscow, 1976, 64 p. (in Russ.).

Received December 18, 2014

Revised January 14, 2015

\footnotetext{
* Corresponding author.
} 